\title{
Changes in Neural Connectivity and Memory Following a Yoga Intervention for Older Adults: A Pilot Study
}

\author{
Harris A. Eyre ${ }^{\mathrm{a}, \mathrm{b}}$, Bianca Acevedo ${ }^{\mathrm{a}}$, Hongyu Yang ${ }^{\mathrm{a}}$, Prabha Siddarth ${ }^{\mathrm{a}}$, Kathleen Van Dyk ${ }^{\mathrm{a}}$, \\ Linda Ercoli ${ }^{\mathrm{a}}$, Amber M. Leaver ${ }^{\mathrm{c}}$, Natalie St. Cyr ${ }^{\mathrm{a}}$, Katherine Narr ${ }^{\mathrm{c}}$, Bernhard T. Baune ${ }^{\mathrm{b}}$, \\ Dharma S. Khalsa ${ }^{\mathrm{d}}$ and Helen Lavretsky ${ }^{\mathrm{a}, *}$ \\ ${ }^{a}$ Semel Institute for Neuroscience and Human Behavior, UCLA, Los Angeles, CA, USA \\ ${ }^{\mathrm{b}}$ Discipline of Psychiatry, University of Adelaide, Adelaide, South Australia, Australia \\ ${ }^{\mathrm{c}}$ Ahmanson-Lovelace Brain Mapping Center, Department of Neurology, UCLA, Los Angeles, CA, USA \\ dAlzheimer's Research and Prevention Foundation, Tucson, AZ, USA
}

Accepted 9 February 2016

\begin{abstract}
.
Background: No study has explored the effect of yoga on cognitive decline and resting-state functional connectivity.

Objectives: This study explored the relationship between performance on memory tests and resting-state functional connectivity before and after a yoga intervention versus active control for subjects with mild cognitive impairment (MCI).

Methods: Participants ( $\geq 55$ y) with MCI were randomized to receive a yoga intervention or active "gold-standard" control (i.e., memory enhancement training (MET)) for 12 weeks. Resting-state functional magnetic resonance imaging was used to map correlations between brain networks and memory performance changes over time. Default mode networks (DMN), language and superior parietal networks were chosen as networks of interest to analyze the association with changes in verbal and visuospatial memory performance.

Results: Fourteen yoga and 11 MET participants completed the study. The yoga group demonstrated a statistically significant improvement in depression and visuospatial memory. We observed improved verbal memory performance correlated with increased connectivity between the DMN and frontal medial cortex, pregenual anterior cingulate cortex, right middle frontal cortex, posterior cingulate cortex, and left lateral occipital cortex. Improved verbal memory performance positively correlated with increased connectivity between the language processing network and the left inferior frontal gyrus. Improved visuospatial memory performance correlated inversely with connectivity between the superior parietal network and the medial parietal cortex.

Conclusion: Yoga may be as effective as MET in improving functional connectivity in relation to verbal memory performance. These findings should be confirmed in larger prospective studies.
\end{abstract}

Keywords: Aging, cognitive decline, memory training, mild cognitive impairment, mind-body, older adults, subjective memory complaints, yoga

\footnotetext{
*Correspondence to: Dr. Helen Lavretsky, Professor of Psychiatry, UCLA; Director, Late life mood stress and wellness research program, 760 Westwood Plaza, Rm 37-465, Los Angeles, CA 90077, USA. Tel.: +1 310794 4619; Fax: +1 3102064399 ; E-mail: hlavretsky@mednet.ucla.edu.
}

\section{INTRODUCTION}

The global population is aging at a rate unprecedented in human history. This increase in aging, whereby over 2 billion people will be $\geq 60$ years of age by 2050 [1], will obviously be paralleled by a rise 
in age-related cognitive impairments. Mild cognitive impairment (MCI) has been noted to range between $10-20 \%$ in samples of population-based studies of older adults [2]. Individuals with MCI have a 2.5fold high risk for developing all-cause dementia, and $\mathrm{MCI}$ is often a precursor to Alzheimer's disease (AD) [2]. MCI is thought to represent a continuum between healthy aging and $\mathrm{AD}[3]$, and thus can be used as models for preventive interventions. As such, there is increasing interest in the neural circuits and other factors that affect and predict progress to $\mathrm{AD}$; as well as novel interventions.

Yoga is one such technique that is rapidly gaining interest and popularity in the West (although it has been used in the East for thousands of years), mainly being used by millions of people for stress-reduction, according to surveys. For example, in England there was a rise from 0.46 to $1.11 \%$ of population between 1999 and 2008 [4]; and in the US, 2012 data suggests $9.5 \%$ of the US population uses yoga therapies [5]. New data is now suggesting that mind-body interventions including yoga, tai chi, mindfulness meditation, and qi gong, have promising effects on cognitive issues related to aging [6-8]. A recent study by Gothe et al. [9] compared the effects of Hatha yoga and stretching-strengthening control on cognition over 8 weeks in 118 community-dwelling older adults, and found significantly improved executive function, working memory and efficiency of mentalset shifting and flexibility in the yoga group compared with the control group. A study by Hariprasad et al. [10] compared yoga with waitlist controls over 6 months among 87 residents of nursing homes in India. Findings showed that individuals in the yoga intervention group showed marked improvements in an array of cognitive domains compared to wait-list controls.

However, there are no studies to date examining functional brain connectivity in relation to memory following a yoga intervention among older adults [11]. In a previous pilot study using Kirtan Kriya (KK, a meditation that involves chanting mantra, hand movements, and visualization), older family dementia caregivers showed significant improvements in cognition, memory, and brain metabolism compared to a relaxation control condition [12]. A pilot study by Wells et al. [13] explored the effect of mindfulnessbased stress reduction (MBSR) versus usual care on neural outcomes among $14 \mathrm{MCI}$ subjects. They explored resting state functional magnetic resonance imaging (rs-fMRI) and structural MRI data around the default mode network (DMN) and hippocampus, and found enhanced DMN activity and lesser bilateral hippocampal atrophy. These results are very relevant for subjects with MCI and AD, which typically affects DMN and hippocampus very early in the disease process, and some have used these are early markers of AD [14].

Memory enhancement training (MET) is another technique that has been increasingly explored for the prevention of cognitive decline, and is thus considered a 'gold-standard' and rigorous control for studies of cognitive impairment. The goal of MET is to optimize cognitive function to support individuals' life functioning and quality of life [15]. There is evidence suggesting that MET promotes significant improvements in cognitive performance among healthy, older adults [16]; however there is no clear consensus on the mechanisms of action underlying reported benefits [17]. A number of systematic reviews have been conducted on the effects of MET in individuals with MCI. For example, one review by Jean et al. [18] analyzed 15 studies and found effects on memory, and quality and life. Simon et al. [19] explored this field for amnestic MCI patient and ground effects on cognitive performance and subjective perceptions of cognition. There are no studies to date exploring the effect of MET on rs-fMRI.

To our knowledge, yoga has never been compared to MET in a direct head-to-head comparative clinical trial and this has not occurred with in vivo imaging biomarkers. In this preliminary study of KK meditation (with weekly Kundalini yoga classes as boosters) and MET, we explored associations between memory improvements and functional plasticity in brain networks relevant for memory. Our primary focus was on the relationship between changes in neural functional connectivity and changes in memory performance.

\section{METHODS}

Data were collected for the "Memory Training Versus Yogic Meditation Training in Older Adults with Subjective Memory Complaints and MCI' study at UCLA from 2013 to 2015 (NCT01983930). This 12-week randomized trial examined the cognitive effects of MET versus KY+KK in older adults with memory concerns and a CDR of 0.5 .

\section{Participants}

Participants were recruited via advertisements from UCLA outpatient clinics and the UCLA Longevity Center Program, and from the community. 
This study was approved by the UCLA Institutional Review Board (IRB). All participants underwent IRB-approved informed consent procedures prior to enrolling in the study.

Inclusion criteria were: 1) age $\geq 55$ years; 2) subjective memory complaints; 3) Clinical Dementia Rating (CDR) Scale score of 0.5 [20]; 3) sufficient English proficiency at the 8th grade level or higher as determined by the word reading subtest of the Wide Range Achievement Test-4 [21] to participate in MET; 4) capacity to provide informed consent.

Exclusion criteria included: 1) current or past Axis I psychiatric disorders, or recent unstable medical or neurological disorders; 2) any disabilities preventing participation in the MET or KY+KK conditions (e.g., severe visual or hearing impairment); 3) insufficient English proficiency; 4) a diagnosis of dementia per the DSM-IV/5; 5) Mini-Mental Health Examination (MMSE) [22] score of 24 or below; 6) use of psychoactive medications; 7) participation in a psychotherapy that involves cognitive training; and 8) participants with prior or current training in yoga.

At baseline, participants underwent a screen including: 1) an interview by a trained study staff to identify physical and cognitive symptoms; 2) a standard battery of hematologic studies; 3) neurological examination (i.e., the Unified Parkinson's Disease Rating Scale (UPDRS) [23]; 3) select memory tests (the Fluid Object Memory Evaluation [24]; and 4) a neuropsychiatric evaluation (Structured Clinical Interview for DSM Disorders) [25]; 5) medical comorbidity was assessed with the Cerebrovascular Risk Factor Prediction Chart [26]; the Cumulative Illness Rating Scale-Geriatric [23, 27-30]; 6) mood assessments included the Geriatric Depression Scale (GDS) [31].

\section{Randomization and blinding procedures}

After all baseline test results were reviewed and eligibility criteria were confirmed, subjects were randomized to either MET or KY groups using a computer-generated random assignment scheme, which assigns subjects in a 1:1 ratio to each group in the blocks of $8-10$ subjects. All groups were called "wellness and mental stimulation" groups. All behavioral raters, the principal investigator, all statisticians and data managers were blind to the group assignment, and subjects were asked not to disclose their group assignment to the raters. No unblinding occurred in the process of assessment.

\section{Neuropsychological assessment schedule}

Participants were assessed at baseline (pretreatment) and at 12-weeks (post-treatment). While an extensive neuropsychological battery was administered for the full trial, the focus of this research was to identify the neural networks associated with memory improvements resulting from a meditation (KK) and MET among older individuals with MCI. The following memory tests were used: A verbal list-learning measure, the Hopkins Verbal Learning Test-Revised (HVLT-R) [32] (20-min delay recall raw scores) and a visuospatial memory measure, the Rey-Osterrieth Complex Test (Rey-O) (30-min delay recall raw scores) [33]. Only HVLT and Rey-O delayed recall change scores were correlated with connectivity changes in this study to compare the effects of interventions on network connectivity specifically associated with long-term memory.

\section{Yoga intervention}

Participants were randomly assigned to the KK meditation group (which included 60-min weekly $\mathrm{KY}$ classes and a 12-min KK meditation daily as a homework assignment). The structure of the 60-min weekly yoga sessions were the same for each group and standard for KY classes conducted by a certified KY yoga teacher. The content and structure of the class did not differ from one week to another and contained the following elements: 1) Tuning in (5 min); 2) Warm up (10 min); 3) Breath techniques "Pranayama" (10 min); 4) Kriya (20 min); 5) Meditation (11 min); 6) Rest "Shavasana" and closing (4 min). KK was taught during the class using standardized CDs for the 12-min meditation. Standardized handouts and CDs were given to each participant for home practice. This protocol is standard for the KK and KY practice and has been utilized in previous studies with older adults [34]. A brief (3-5 min) warm-up with 12-min yogic practice includes an ancient chanting meditation, KK, performed every day at the same time for a total of 12 weeks, using a previously tested protocol. The meditation involves repetitive finger movements (or mudras), as well as chanting of the mantra "Saa, Taa, Naa, Maa," meaning "Birth, Life, Death, and Rebirth," first chanted aloud, then in a whisper, and silently for the total of $11 \mathrm{~min}$ followed by 1-min of the final deep breathing relaxation accompanied by the visualization of light [35]. Adverse events were 
monitored at each visit by using the UKU Side Effect Rating Scale [36].

\section{Memory enhancement training}

Developed at the UCLA Longevity Center by Dr. Ercoli and colleagues, MET involves a scripted curriculum for trainers and a companion workbook for participants. The standard detailed protocol for the MET program is based on evidence-based techniques that use verbal and visual association strategies and practical strategies for memory compensation [16, 37]. MET is manualized and includes several components common to effective memory training programs [16] such as: (1) education about memory; (2) preliminary instruction in the basic elements of memory strategies (i.e., "pre-training"); (3) instruction in specific memory strategies; (4) home practice with logs to track activity; (5) addressing non-cognitive factors such as self-confidence, anxiety, and negative expectations; and (6) small (i.e., about 10 persons) groups and short (60-min) sessions. The curriculum is divided into 12 weekly-sessions that are organized in the same way in which trainers: (1) document the number of participants attending the session, collect homework completion logs and assess engagement in alternative treatments; (2) review the previous session's homework to reinforce techniques; (3) teach new techniques, reviews, and conduct in-class exercises; and (4) assign homework. Each session is devoted to learning and practicing techniques, and $15 \mathrm{~min}$ are reserved for reviewing homework. Specific techniques taught include: Visual associative strategies for learning faces and names (adapted from McCarthy [38]); verbal associative techniques (such as the use of stories) to remember lists; organizational strategies (categorizing items on a grocery list); learning memory habits to recall where one places items, what one has done in the recent past (e.g., locking doors, turning off appliances); and how to remember future tasks (i.e., appointments).

\section{Neuroimaging acquisition and preprocessing}

\section{Image acquisition}

Resting-state (rs) fMRI data were collected with a 3T TIM Trio scanner (Siemens AG, Munich \& Berlin, Germany) at baseline and at 12-weeks (immediately post-intervention). Participants' heads were positioned comfortably within a 32-channel head coil, and head motion was minimized with firm cushions. We instructed participants to close their eyes and stay awake during image acquisition. RS-fMRI images were acquired for $5 \mathrm{~min}$ and $41 \mathrm{~s}$ with a multi-band gradient-echo echo-planar imaging (EPI) sequence sensitive to BOLD contrast effects. We acquired 275 contiguous EPI resting-state volumes, and the parameters for functional imaging were: Repetition time $1.24 \mathrm{~s}$, echo time $38.2 \mathrm{~ms}$, flip angle $65^{\circ}$, field of view $21.2 \times 21.2 \mathrm{~cm}^{2}$, acquisition matrix $118 \times 118,1.8 \mathrm{~mm}^{3}$ iso-voxel size (no gap), 78 slices, and 6 bands. We also acquired anatomic images with 3-dimensional MPRAGE sequence (acquisition matrix $256 \times 256$ with $1 \mathrm{~mm}$ thick contiguous slices) for co-registration with the rs-fMRI data.

\section{Image preprocessing}

Brain imaging data were pre-processed using FSL (FMRIB Software Library (FSL, www.fmrib.ox. ac.uk/fsl) for motion correction, high-pass filter $(0.01 \mathrm{~Hz})$, image normalization and $5-\mathrm{mm}^{3}$ Gaussian spatial smoothing. MELODIC (Multivariate Exploratory Linear Decomposition into Independent Components, a tool of FSL) was used to remove significant brain motion, scanner, and physiological artifacts using independent component analysis (ICA). The processed functional data from all participants were temporally concatenated to form a 4-dimensional data set, which was decomposed into group-level independent components (ICs) using ICA as implemented in MELODIC. The MELODIC automated dimensionality estimate was used to determine the number and order of the ICs [39]. Twenty-five ICs were identified with this method. Each component includes brain structures that share the same temporal pattern of signal after mixture modeling was applied. The dual regression approach was subsequently used to back-reconstruct individual-specific connectivity maps associated with each group-level component, which been shown to be an effective and reliable approach to analyses of resting state fMRI data [40]. This approach yielded 36 ICs; 26 of these overlapped grey matter and were considered biologically plausible and considered for subsequent statistical analysis (described below).

\section{Statistical analysis}

The two groups were compared on all demographic and clinical measures at baseline to assess that randomization procedures were effective. We used Fisher's exact tests for the categorical measures and Wilcoxon-Mann-Whitney tests for the continuous 


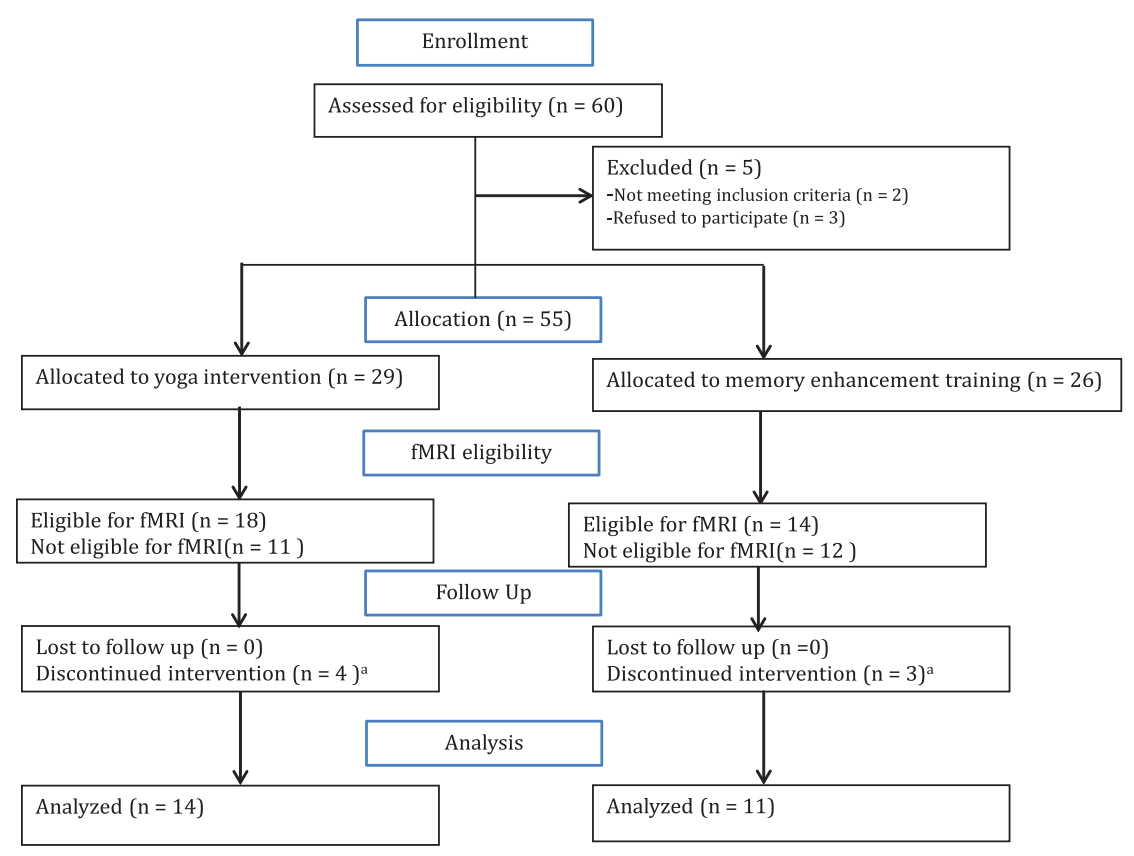

Fig. 1. Flow diagram of participants through trial. ${ }^{\text {a }}$ Due to lack of interest in the intervention or inability to commit to study schedule.

measures. Changes in clinical and the memory measures were examined between groups using Wilcoxon-Mann-Whitney tests and within groups using Wilcoxon signed rank tests. A significance level of 0.05, two-tailed was used for all inferences.

The present study focused primarily on 4 ICs for analyses, based on group level ICs relevant to the tests of long-term memory, including: The DMN, posterior DMN, language network, and superior parietal network. For each IC, we analyzed correlations between voxel-wise changes in network connectivity and changes in memory performance across all the participants (using years of education, age, sex, and days of training duration as covariates). These analyses were restricted to component-specific masks generated by thresholding the group-level IC probability image to voxels having 0.5 or higher probability of contributing to each IC map. Voxel-wise thresholds were chosen at $z<2.3 p<0.01$, and corrected for cluster-size using Random Field Theory at $p$ (corr) $<0.05$. Finally, we conducted post-hoc region of interest (ROI) analyses, assessing correlations for each intervention group (yoga and MET) separately between changes in functional connectivity and changes in memory scores. In these post-hoc ROI analyses, outliers were identified using Cook's distance (d) and removed as appropriate.

\section{RESULTS}

Figure 1 presents the Consolidated Standards of Reporting Trials (CONSORT) flow. Groups were statistically equivalent across all measures at baseline. Table 1 presents the baseline clinical and demographic characteristics of the intervention. Twenty-five individuals total were involved in this study with: 14 individuals in the yoga group (mean age of $67.1 \pm 9.5$ years) and 11 individuals in the MET group (mean age of $67.8 \pm 9.7$ years).

Change scores did not significantly differ between the two groups in most of the clinical or memory measures; however the yoga group improved significantly in depression (GDS) and in visuospatial memory (Rey-O delayed recall). The clinical improvement in GDS for the yoga group was only minimal (baseline 7.5 (5.1) and follow up $3.9(2.5) ; p=0.01)$.

In terms of functional connectivity, we focused our analyses on four components related to longterm memory (the DMN, posterior DMN, language network, and superior parietal network). Results showed significant correlations between changes in connectivity and long-term declarative memory performance alterations for both groups after training $(p$ (corr $<0.05)$. These components are described in detail in the sections below. 
Table 1

Demographic and clinic measures for yoga and memory enhancement training groups

\begin{tabular}{|c|c|c|c|c|c|}
\hline & \multicolumn{2}{|c|}{$\begin{array}{c}\text { Yoga Group } \\
(n=14) \text { Mean (SD) }\end{array}$} & \multicolumn{2}{|c|}{$\begin{array}{c}\text { MET Group } \\
(n=11) \text { Mean (SD) }\end{array}$} & Analysis \\
\hline$\overline{\text { Age (years) }}$ & \multicolumn{2}{|c|}{$67.1(9.5)$} & \multicolumn{2}{|c|}{$67.8(9.7)$} & Wilcoxon test, $p=0.8$ \\
\hline Education & \multicolumn{2}{|c|}{$16.8(1.7)$} & \multicolumn{2}{|c|}{$16.2(1.6)$} & Wilcoxon test, $p=0.4$ \\
\hline Sex & \multicolumn{2}{|c|}{$\mathrm{N}(\%)$} & \multicolumn{2}{|c|}{$\mathrm{N}(\%)$} & Fisher's exact $p=0.7$ \\
\hline Male & \multicolumn{2}{|c|}{$8(57)$} & \multicolumn{2}{|c|}{$5(45)$} & \\
\hline Female & \multicolumn{2}{|c|}{$6(43)$} & \multicolumn{2}{|c|}{$6(55)$} & \\
\hline Race & \multirow{2}{*}{\multicolumn{2}{|c|}{$12(86)$}} & & & Fisher's exact $p=0.6$ \\
\hline White & & & \multicolumn{2}{|c|}{$8(73)$} & \\
\hline Other & \multicolumn{2}{|c|}{$2(14)$} & \multicolumn{2}{|c|}{$3(27)$} & \\
\hline Handedness & & & & Fisher's exact $p=0.6$ \\
\hline Left & \multirow{2}{*}{\multicolumn{2}{|c|}{$\begin{array}{c}2(14) \\
12(86)\end{array}$}} & \multicolumn{2}{|c|}{$3(27)$} & \\
\hline Right & & & \multicolumn{2}{|c|}{$8(73)$} & \\
\hline MMSE & \multicolumn{2}{|c|}{$28.7(1.3)$} & \multicolumn{2}{|c|}{$29.1(0.7)$} & Wilcoxon test, $p=0.7$ \\
\hline Clinical Measures & Baseline & Follow-up & Baseline & Follow-up & $\begin{array}{l}\text { Wilcoxon signed rank } \\
\text { test of within group changes* }\end{array}$ \\
\hline$\overline{\text { GDS }}$ & $7.5(5.1)$ & $3.9(2.5)$ & $5.7(5.6)$ & $3.2(2.5)$ & Yoga: $p=0.01 ;$ MET: $p=0.08$ \\
\hline CVRF & $8.3(5.2)$ & $8.8(4.6)$ & $6.6(4.8)$ & $8.4(5.8)$ & Yoga: $p=0.9 ;$ MET: $p=0.4$ \\
\hline CIRS total & $1.7(2.0)$ & $1.4(1.6)$ & $2.3(1.8)$ & $2.2(1.9)$ & Yoga: $p=1.0 ;$ MET: $p=1.0$ \\
\hline HVLT delayed & $9.1(3.3)$ & $9.9(1.9)$ & $8.6(2.6)$ & $10.1(1.9)$ & Yoga: $p=0.5 ;$ MET: $p=0.1$ \\
\hline Rey-O delayed & $18.2(5.0)$ & $22.2(6.0)$ & $18.4(5.1)$ & $20.1(6.0)$ & Yoga: $p=0.03 ;$ MET: $p=0.1$ \\
\hline
\end{tabular}

GDS, Geriatric Depression Scale; CVRF, Cardiovascular Risk Factors; CIRS, Cumulative Illness Rating Scale; MMSE, Mini-Mental State Examination; Rey-O delayed, Rey-Osterrieth complex figure delayed recall; HVLT delayed, Hopkins Verbal Learning Test delayed recall. *No significant between group differences (Wilcoxon tests all $p$-values $>0.1$ ).

\section{Default mode network findings for yoga and memory enhancement training}

In our analyses, we identified two DMNs. The first included regions most typically associated with the DMN, including the precuneus, PCC, ACC, medial frontal cortex (MFC), and hippocampus. The second DMN was more posterior and included precuneus, PCC, lateral parietal cortex, and hippocampus. No significant effects were identified in this latter posterior DMN. Results within the more typical DMN are discussed below.

In analyses of the DMN (Fig. 2), improvement in the HVLT delayed recall in both in yoga and MET groups correlated with greater connectivity in two anterior clusters, the pregenual ACC and frontal medial cortex (FMC). ROI analyses confirmed the effects were present in both groups for the ACC $\left(\mathrm{R}_{14}=0.84, p<0.001\right.$ for yoga subjects; $\mathrm{R}_{11}=0.73$, $p=0.011$ for MET subjects). The correlations were still statistically significant after removal of an outlier in the yoga group (Cook's Distance $=0.81$ ) $\left(\mathrm{R}_{13}=0.62, p=0.024\right.$ for yoga subjects). Correlations were also significant for both groups in ROI analyses of the FMC $\left(\mathrm{R}_{14}=0.91, p<0.001\right.$ for yoga group; $\mathrm{R}_{11}=0.64, p=0.035$ for MET group). Similarly, the FMC correlation remained significant after the removal of an outlier in the yoga group (Cook's
Distance $=2.3) \quad\left(\mathrm{R}_{13}=0.76, \quad p=0.002\right.$ for yoga group). See Fig. 2.

Increased HVLT delayed recall positively correlated with increased DMN-connectivity within two posterior clusters: The PCC and left lateral occipital cortex. In ROI analyses, this positive correlation was present for both groups in the PCC $\left(\mathrm{R}_{14}=0.78\right.$, $p=0.001$ for yoga group; $\mathrm{R}_{11}=0.68, p=0.02$ for MET group). However, the correlation in the PCC was not significant after removal of an outlier in the yoga group $\left(\mathrm{R}_{13}=0.47, p=0.106\right)$ (Cook's Distance $=0.86$ ). Increased HVLT delayed recall was also correlated with increased connectivity within the left lateral occipital cortex for both groups in ROI analyses $\left(\mathrm{R}_{14}=0.81, p<0.001\right.$ for yoga group; $\mathrm{R}_{11}=0.77$, $p=0.005$ for MET group). This correlation remained borderline significant after removal of an outlier in the yoga group $\left(\mathrm{R}_{13}=0.51, p=0.077\right.$ for yoga group $)$.

An additional cluster in the dorsolateral prefrontal cortex (middle frontal gyrus) also showed increased connectivity in association with increased HVLT delayed recall scores. ROI analyses indicated the effect was present in both groups $\left(\mathrm{R}_{14}=0.87\right.$, $p<0.001$ for yoga group; $\mathrm{R}_{11}=0.68, p=0.02$ for MET group). The correlation remained significant after removal of an outlier for the yoga group $\left(\mathrm{R}_{13}=0.62, p=0.025\right.$ for yoga group) (Cook's Distance $=3.1$ ). 
A

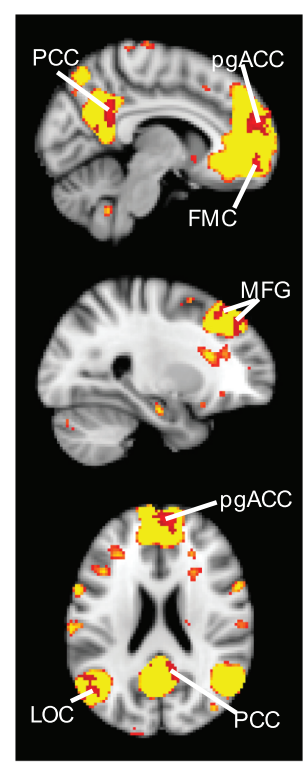

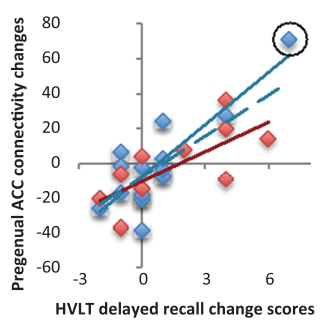

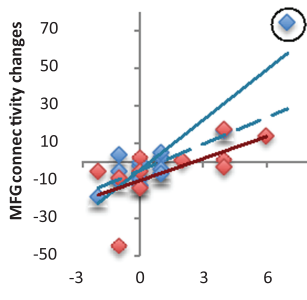

HVLT delayed recall change scores
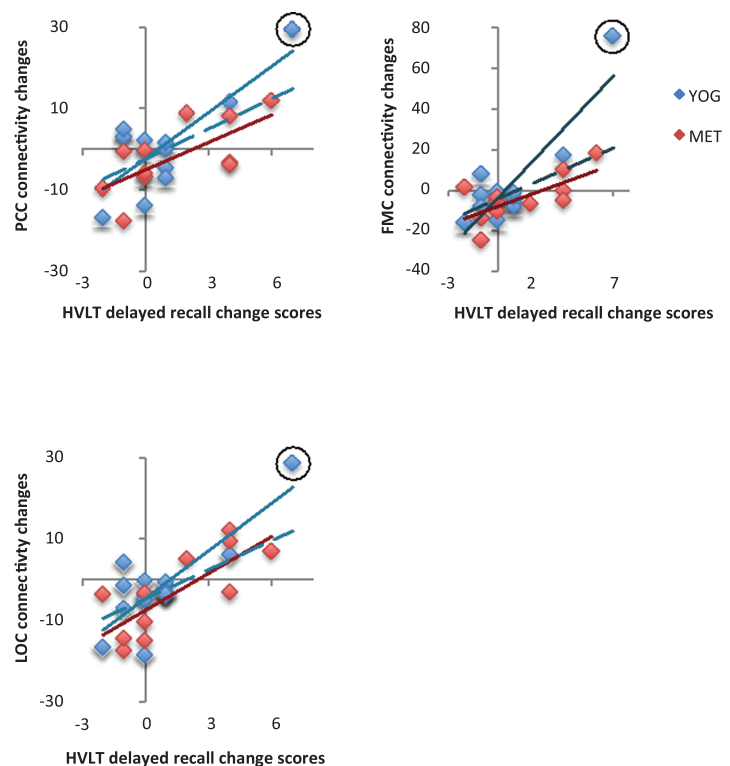

Fig. 2. Changes in functional connectivity within the default mode network correlated with improved verbal memory performance. A) The default mode network (DMN) is displayed in yellow on a template brain in neurological convention. Regions that exhibited significant correlations between changes in DMN connectivity and changes in HVLT delayed recall are shown in red $(z>2.3, p<0.05$, corrected). All correlations were positive, and significant clusters included the pregenual anterior cingulate cortex (ACC), frontal medial cortex (FMC), posterior cingulate cortex (PCC), middle frontal gyrus (MFG), and lateral occipital cortex (LOC). B) Scatter plots indicate positive correlations in the clusters displayed in A in yoga (YOG, blue) and memory enhancement training (MET, red) groups. Trendlines are plotted for each group; dashed lines indicate trendlines without the outlier (marked with a black circle) for the yoga group.

\section{Language network findings for yoga and memory enhancement training}

The language resting-state network included the bilateral frontal orbital cortex, superior frontal gyrus, left middle and inferior frontal gyrus, dorsal anterior cingulate cortex, left middle and superior temporal gyrus, and angular gyrus. Subjects showed positive correlations between long-term verbal memory performance changes and altered functional connectivity in one cluster, the left inferior frontal gyrus (IFG). ROI analyses indicated that this positive correlation was present for both groups $\left(\mathrm{R}_{14}=0.82, p<0.001\right.$ for yoga group; $\mathrm{R}_{11}=0.55, p=0.079$ for MET group). However, the correlation was not significant after removal of an outlier for the yoga group $\left(\mathrm{R}_{13}=0.42\right.$, $p=0.15)$. See Fig. 3 .

\section{Superior parietal network findings for yoga and memory enhancement training}

The superior parietal network (known for its role in long-term and working memory [41]) included the bilateral PCC, precuneus, precentral and postcentral gyrus, and parietal operculum cortex. With respect to this network, a single cluster near the precentral and postcentral gyri exhibited a negative relationship between changes in functional connectivity and changes in long-term visuospatial memory performance. In an ROI analysis, both the yoga and MET groups showed significant effects in this cluster $\left(\mathrm{R}_{14}=-0.59, p=0.028\right.$ for yoga group; $\mathrm{R}_{11}=-0.73$, $p=0.011$ for MET group). See Fig. 4 .

\section{DISCUSSION}

The present study was the first to examine changes in neural connectivity and memory associated with a yoga intervention (specifically KK) and MET among a group of elderly individuals experiencing MCI. Overall, we found comparable changes for both yoga and MET in neural connectivity networks associated with memory performance.

Both the yoga and MET group showed restingstate brain activity changes reflecting improvements in memory. Mainly, results showed increased connectivity within DMN and the language network in association with improved verbal memory performance for both Yoga and MET groups. Changes in the superior parietal network were also negatively 
A

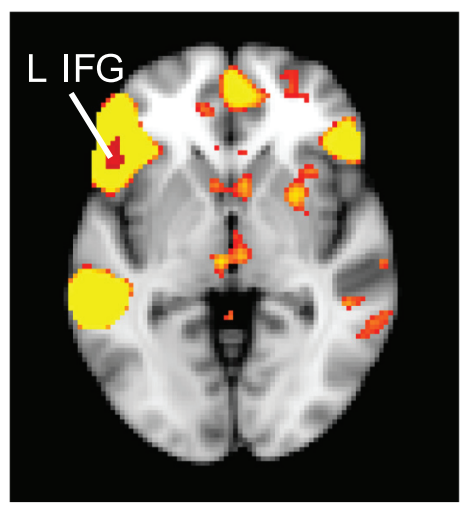

B

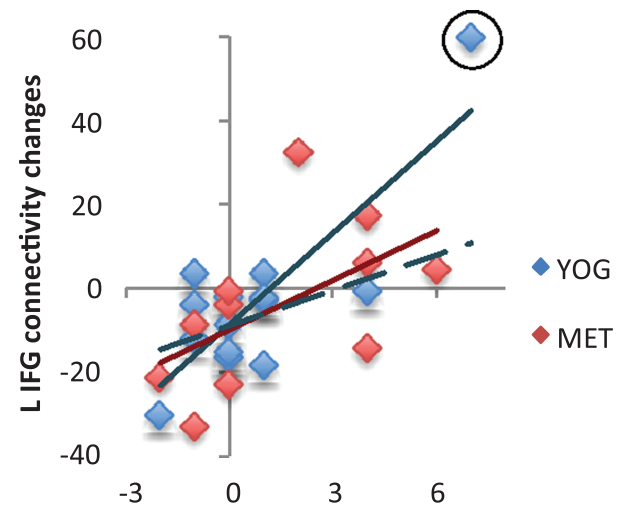

HVLT delayed recall change scores

Fig. 3. Changes in functional connectivity within the language network correlated with improved verbal memory. A) The language restingstate network is displayed in yellow on a template brain in neurological orientation. A single region in the left inferior frontal gyrus (L IFG) showed a significant positive correlation between changes in language-network connectivity and improved verbal memory measured with the Hopkins Verbal Learning Test (HVLT). This region is displayed in red $(z<2.3, p<0.05$, corrected). B) A scatter figure displays the positive correlation for the L IFG cluster shown in A for yoga (YOG, blue) and memory enhancement training (MET, red) groups. Trendlines are displayed for each group, including a dashed line for a trendline with an outlier (circled in black) removed for the yoga group.
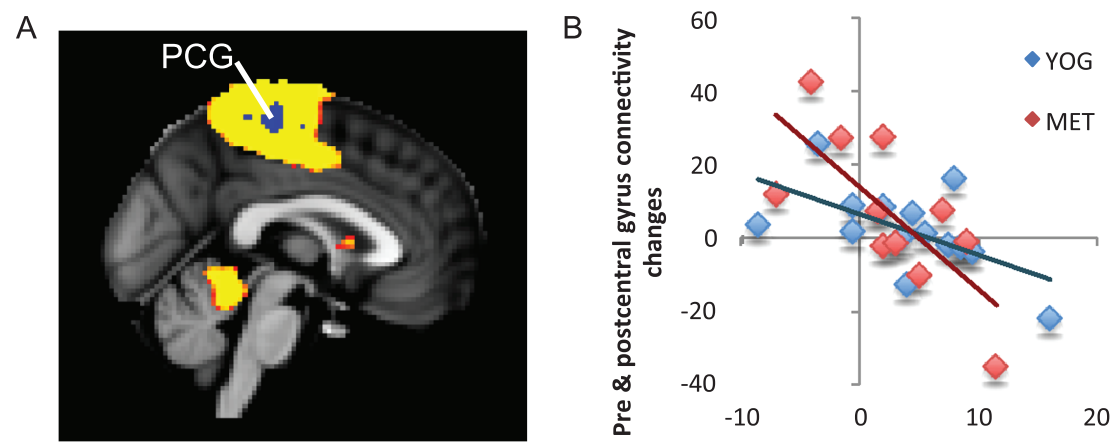

Rey-O delayed recall change scores

Fig. 4. Changes in functional connectivity within the superior parietal network correlated with changes in visuospatial memory. A) The superior parietal resting-state network is displayed in yellow on a template brain. A single region near the pre- and post-central gyri (PCG) showed significant negative correlation between changes in connectivity with the superior parietal network and changes in visuospatial memory measured by the Rey-Osterrieth Complex Figure Test (Rey-O). This cluster is displayed in blue $(z<2.3, p<0.05$, corrected). B) A scatter figure displays the negative correlation for the PCG cluster displayed in A for the yoga (YOG, blue) and memory enhancement training (MET, red) groups. Trendlines are displayed for each group.

correlated with memory recall improvements. We discuss these findings in detail below.

The DMN is a network of regions showing synchronized activity patterns when the brain is at-rest and decreased when the mind is engaged in the external environment $[42,43]$. The DMN includes areas in the medial prefrontal cortex, the PCC, precuneus and medial temporal lobe structures including the hippocampus [44, 45]. Evidence suggests involvement of the DMN in episodic memory retrieval, prospective memory encoding, social cognition, selfreferential processing, including self-prospecting and internal monitoring, autobiographical memory retrieval, future planning, and theory of mind [45-47]. Some research suggests that the DMN is the main rs-fMRI network affected in aging [48-51], showing reductions in connectivity between anterior and posterior nodes [48, 49, 52-56]. Decreased DMN connectivity has been noted in AD [57] and involves areas affected by cerebral atrophy, reduced metabolism, and amyloid in AD and MCI [58]. The suggestion for alterations of DMN connectivity has been previously attributed to inefficiency reallocation of brain resources. From a neuroanatomical perspective this may be due to poorer cingulum bundle integrity which connects posterior to anterior and 
temporal DMN nodes [59]. Poorer antero-posterior connectivity was recently correlated with visual and verbal memory scores in a study of 116 healthy elders [55].

Our study findings suggest that yoga may be helpful in enhancing memory recall, specifically visual memory encoding. However, we acknowledge that practice effects may factor into observed improvements. Moreover, these findings suggest that improved memory recall is associated with increased DMN connectivity in anterior, posterior and frontal medial areas. Relevant to these findings are a number of other studies. A pilot study by Wells et al. [13] explored the effect of MBSR versus usual care on 14 MCI subjects. They explored rs-fMRI and structural MRI data around the DMN and hippocampus, respectively. The study found enhanced DMN activity (increased functional connectivity between the PCC and medial prefrontal cortices and hippocampus), as well as lesser bilateral hippocampal atrophy. These results are promising given that these regions are associated with MCI and AD. Yoga is believed to exert its effect via lowering stress, lowering inflammation, enhancing neuroplasticity processes (e.g., production of brain derived neurotrophic factor), increasing antioxidant levels and increasing telomerase activity [12, 60-64].

A number of studies have explored the effect of meditative therapies on the DMN, supporting the present study findings. For example, Taylor et al. [65] recently compared DMN functional connectivity between 13 experienced meditators and 11 beginner meditators; and found that experienced meditators had weaker functional connectivity between DMN regions involved in self-referential processing and emotional appraisal, however they showed greater connectivity in regions associated with present-moment awareness. It is likely that present-moment awareness facilitates verbal memory, processing and recall as the individual is attentive to the moment. Brewer et al. [66] conducted a similar analysis of experienced meditators versuss meditation-näive controls across a number of difference meditation types, i.e., concentration, loving-kindness, and choice-less awareness. Experienced meditators showed deactivation in the main nodes of the DMN (MFC and PCC) across all meditation types; as well as stronger coupling between the PC, dorsal ACC and dorsolateral prefrontal cortices at both baseline and during meditation. This suggests enhanced efficiency of self-monitoring and cognitive control among experienced meditators. Given the complex nature of KK meditation (as it involves chanting, hand movements, and visualization), we believe that it engages language, visual and frontal networks important for self-regulation resulting in enhanced verbal and visual memory as shown in the present study. Other proposed potential mechanisms are via stress reduction and increased global attention/awareness.

Improved visual-spatial memory performance correlated inversely with connectivity in the superior parietal network, which has been shown to be associated with attention, translation of visual to motor information, and working memory [41, 67]. It is possible that these network connectivity changes reflect enhanced efficiency of connectivity between the relevant brain regions (i.e., between the bilateral posterior cingulate cortex, precuneus cortex, precentral, postcentral gyrus, and parietal operculum cortex). The less-wiring-more-firing hypothesis suggests that greater activity of neurons in older age compensates for impaired white-matter connectivity, that there is an over-recruitment of neuronal activity for functional compensation [68]. In this study, we suggest that yoga improves white-matter connectivity thereby reducing neuronal activity with the result of improved visuospatial memory performance. This hypothesis can be tested more accurately with the use of diffusion tensor imaging which measures whitematter integrity.

Although there are several limitations we believe that the findings are promising, as we used strong control group (MET) and found significant connectivity changes even with a small sample size that are in-line with previous findings. The sample size was only powered towards rs-fMRI findings, and exploring relationships between memory and functional connectivity, not exploring multi-domain effects on cognition. Additionally, we do not have long-term follow-up, which means we are unable to explore cognitive decline towards dementia. Also, it is possible that the enhanced cognitive benefits and connectivity changes resulting from the KK yogic intervention were due to the $60 \mathrm{~min}$ of instruction per week, the 12 min per day of Kirtan kriya meditation (shown to positively affect blood flow in the brain [34]), or a combination of these factors. However, as previous studies only using KK meditation found activation patterns that are in-line with those from the present research, it is unlikely that the weekly classes presented a large deviation. Nevertheless, this is a fruitful area for future research studies, which may aim to parse out the effects of these various activities, or 
perhaps determine that for optimal benefits weekly classes in addition to a daily meditative practice is recommended.

\section{CONCLUSION}

The present study examining resting state neural connectivity changes among individuals undergoing a KK yoga intervention versus MET showed that both were as effective in improving memory functions (namely memory recall) and functional connectivityrelated to verbal, attentional, and self-regulatory performance. The improvement in verbal and visuospatial memory performance may be explained by the use of the components of the chanting mantra meditation (Kirtan Kriya) with visualization that may strengthen specific verbal and visual skills, and enhance global awareness and attention.

\section{ACKNOWLEDGMENTS}

Alzheimer's Research and Prevention Foundation provided funding for this study. Other sources of funding: NIH grants MH077650 and MH086481, contracts from the Forest Research Institute to Dr. Lavretsky.

Authors' disclosures available online (http://jalz.com/manuscript-disclosures/15-0653r1).

\section{REFERENCES}

[1] United Nations, Department of Economic and Social Affairs, Population Division (2013) World Population Ageing 2013. ST/ESA/SER.A/348.

[2] Petersen RC (2011) Clinical practice. Mild cognitive impairment. N Engl J Med 364, 2227-2234.

[3] Petersen RC, Smith GE, Waring SC, Ivnik RJ, Tangalos EG, Kokmen E (1999) Mild cognitive impairment: Clinical characterization and outcome. Arch Neurol 56, 303-308.

[4] Norton S, Matthews FE, Barnes DE, Yaffe K, Brayne C (2014) Potential for primary prevention of Alzheimer's disease: An analysis of population-based data. Lancet Neurol 13, 788-794.

[5] Dossett ML, Davis RB, Lembo AJ, Yeh GY (2014) Complementary and alternative medicine use by US adults with gastrointestinal conditions: Results from the 2012 National Health Interview Survey. Am J Gastroenterol 109, 17051711.

[6] Abbott R, Lavretsky H (2013) Tai Chi and Qigong for the treatment and prevention of mental disorders. Psychiatr Clin North Am 36, 109-119.

[7] Siddarth D, Siddarth P, Lavretsky H (2014) An observational study of the health benefits of yoga or tai chi compared with aerobic exercise in community-dwelling middle-aged and older adults. Am J Geriatr Psychiatry 22, 272-273.
[8] Lavretsky H (2009) Complementary and alternative medicine use for treatment and prevention of late-life mood and cognitive disorders. Aging Health 5, 61-78.

[9] Gothe NP, Kramer AF, McAuley E (2014) The effects of an 8-week Hatha yoga intervention on executive function in older adults. J Gerontol A Biol Sci Med Sci 69, 1109-1116.

[10] Hariprasad VR, Koparde V, Sivakumar PT, Varambally S, Thirthalli J, Varghese M, Basavaraddi IV, Gangadhar BN (2013) Randomized clinical trial of yoga-based intervention in residents from elderly homes: Effects on cognitive function. Indian J Psychiatry 55, S357-S363.

[11] Marchand WR (2014) Neural mechanisms of mindfulness and meditation: Evidence from neuroimaging studies. World J Radiol 6, 471-479.

[12] Lavretsky H, Epel ES, Siddarth P, Nazarian N, Cyr NS, Khalsa DS, Lin J, Blackburn E, Irwin MR (2013) A pilot study of yogic meditation for family dementia caregivers with depressive symptoms: Effects on mental health, cognition, and telomerase activity. Int J Geriatr Psychiatry 28, 57-65.

[13] Wells RE, Yeh GY, Kerr CE, Wolkin J, Davis RB, Tan Y, Spaeth R, Wall RB, Walsh J, Kaptchuk TJ, Press D, Phillips RS, Kong J (2013) Meditation's impact on default mode network and hippocampus in mild cognitive impairment: A pilot study. Neurosci Lett 556, 15-19.

[14] Ahdidan J, Raji CA, DeYoe EA, Mathis J, Noe KO, Rimestad J, Kjeldsen TK, Mosegaard J, Becker JT, Lopez O (2015) Quantitative neuroimaging software for clinical assessment of hippocampal volumes on MR imaging. J Alzheimers Dis 49, 723-732.

[15] Flak MM, Hernes SS, Skranes J, Lohaugen GC (2014) The Memory Aid study: Protocol for a randomized controlled clinical trial evaluating the effect of computer-based working memory training in elderly patients with mild cognitive impairment (MCI). Trials 15, 156.

[16] Verhaeghen P, Marcoen A, Goossens L (1992) Improving memory performance in the aged through mnemonic training: A meta-analytic study. Psychol Aging 7, 242-251.

[17] Olchik MR, Farina J, Steibel N, Teixeira AR, Yassuda MS (2013) Memory training (MT) in mild cognitive impairment (MCI) generates change in cognitive performance. Arch Gerontol Geriatr 56, 442-447.

[18] Jean L, Bergeron ME, Thivierge S, Simard M (2010) Cognitive intervention programs for individuals with mild cognitive impairment: Systematic review of the literature. Am J Geriatr Psychiatry 18, 281-296.

[19] Simon SS, Yokomizo JE, Bottino CM (2012) Cognitive intervention in amnestic Mild Cognitive Impairment: A systematic review. Neurosci Biobehav Rev 36, 1163-1178.

[20] Hughes CP, Berg L, Danziger WL, Coben LA, Martin RL (1982) A new clinical scale for the staging of dementia. $\mathrm{Br}$ J Psychiatry 140, 566-572.

[21] Wilkinson GS, Robertson GJ (2006) Wide Range Achievement Test 4 professional manual, Psychological Assessment Resources, Lutz, FL.

[22] Folstein MF, Folstein SE, McHugh PR (1975) Mini-mental state. A practical method for grading the cognitive state of patients for the clinician. J Psychiatr Res 12, 189-198.

[23] Fahn S, Elton R, et al., (1987) Unified Parkinson's Disease Rating Scale. In Recent Developments in Parkinson's Disease, Fahn S, Marsden C, Goldstein M, Calne D, eds. Macmillan Healthcare Information, Florham Park, NJ.

[24] Fuld PA, Masur DM, Blau AD, Crystal H, Aronson MK (1990) Object-memory evaluation for prospective detection of dementia in normal functioning elderly: 
Predictive and normative data. J Clin Exp Neuropsychol 12, 520-528.

[25] First MB, Gibbon M, Spitzer RL, Williams JBW, Benjamin L (1996) User's guide for the Structured Clinical Interview for DSM-IV Axis I Disorders-Research version-(SCID-I), Version 2.0. Biometrics Research Department, New York State Psychiatric Institute, New York.

[26] Truelsen T, Lindenstrom E, Boysen G (1994) Comparison of probability of stroke between the Copenhagen City Heart Study and the Framingham Study. Stroke 25, 802-807.

[27] American Heart Association (1990) Stroke Risk Factor Prediction Chart Dallas, TX

[28] Endicott J, Nee J, Harrison W, Blumenthal R (1993) Quality of Life Enjoyment and Satisfaction Questionnaire: A new measure. Psychopharmacol Bull 29, 321-326.

[29] Miller MD, Paradis CF, Houck PR, Mazumdar S, Stack JA, Rifai AH, Mulsant B, Reynolds CF (1992) Rating chronic medical illness burden in geropsychiatric practice and research: Application of the Cumulative Illness Rating Scale. Psychiatry Res 41, 237-248.

[30] Ware JEJ, Kosinski M, Keller SD (1994) SF-36 physical and mental health summary scores: A user's manual, The Health Institute, New England Medical Center, Boston, MA.

[31] Yesavage JA, Brink TL, Rose TL, Lum O, Huang V, Adey M, Leirer VO (1982) Development and validation of a geriatric depression screening scale: A preliminary report. $J$ Psychiatr Res 17, 37-49.

[32] Shapiro AM, Benedict RH, Schretlen D, Brandt J (1999) Construct and concurrent validity of the Hopkins Verbal Learning Test-revised. Clin Neuropsychol 13, 348-358.

[33] Shin MS, Park SY, Park SR, Seol SH, Kwon JS (2006) Clinical and empirical applications of the Rey-Osterrieth Complex Figure Test. Nat Protoc 1, 892-899.

[34] Newberg AB, Wintering N, Khalsa DS, Roggenkamp H, Waldman MR (2010) Meditation effects on cognitive function and cerebral blood flow in subjects with memory loss: A preliminary study. J Alzheimers Dis 20, 517-526.

[35] ARPF, Alzheimer's Research \& Prevention Foundation: ARPF Research: Kirtan Kriya, http://www.alzh eimersprevention.org/kirtan_kriya.htm.

[36] Lingjaerde O, Ahlfors UG, Bech P, Dencker SJ, Elgen K (1987) The UKU side effect rating scale. A new comprehensive rating scale for psychotropic drugs and a cross-sectional study of side effects in neuroleptic-treated patients. Acta Psychiatr Scand Suppl 334, 1-100.

[37] Gross AL, Rebok GW (2011) Memory training and strategy use in older adults: Results from the ACTIVE study. Psychol Aging 26, 503-517.

[38] McCarty DL (1980) Investigation of a visual imagery mnemonic device for acquiring face-name associations. J Exp Psychol Hum Learn 6, 145-155.

[39] Beckmann CF, Smith SM (2004) Probabilistic independent component analysis for functional magnetic resonance imaging. IEEE Trans Med Imaging 23, 137-152.

[40] FMRIB, Dual Regression, http://fsl.fmrib.ox.ac.uk/fsl/ fslwiki/DualRegression, Accessed 05/08-15.

[41] Koenigs M, Barbey AK, Postle BR, Grafman J (2009) Superior parietal cortex is critical for the manipulation of information in working memory. J Neurosci 29, 1498014986.

[42] Fox MD, Raichle ME (2007) Spontaneous fluctuations in brain activity observed with functional magnetic resonance imaging. Nat Rev Neurosci 8, 700-711.

[43] Raichle ME, MacLeod AM, Snyder AZ, Powers WJ, Gusnard DA, Shulman GL (2001) A default mode of brain function. Proc Natl Acad Sci U S A 98, 676-682.
[44] Yeo BT, Krienen FM, Sepulcre J, Sabuncu MR, Lashkari D, Hollinshead M, Roffman JL, Smoller JW, Zollei L, Polimeni JR, Fischl B, Liu H, Buckner RL (2011) The organization of the human cerebral cortex estimated by intrinsic functional connectivity. J Neurophysiol 106, 1125-1165.

[45] Buckner RL, Andrews-Hanna JR, Schacter DL (2008) The brain's default network: Anatomy, function, and relevance to disease. Ann N Y Acad Sci 1124, 1-38.

[46] Spreng RN, Mar RA, Kim AS (2009) The common neural basis of autobiographical memory, prospection, navigation, theory of mind, and the default mode: A quantitative metaanalysis. J Cogn Neurosci 21, 489-510.

[47] Northoff G, Bermpohl F (2004) Cortical midline structures and the self. Trends Cogn Sci 8, 102-107.

[48] Andrews-Hanna JR, Snyder AZ, Vincent JL, Lustig C, Head D, Raichle ME, Buckner RL (2007) Disruption of largescale brain systems in advanced aging. Neuron 56, 924-935.

[49] Bluhm RL, Osuch EA, Lanius RA, Boksman K, Neufeld RW, Theberge J, Williamson P (2008) Default mode network connectivity: Effects of age, sex, and analytic approach. Neuroreport 19, 887-891.

[50] Damoiseaux JS, Beckmann CF, Arigita EJ, Barkhof F, Scheltens P, Stam CJ, Smith SM, Rombouts SA (2008) Reduced resting-state brain activity in the default network in normal aging. Cereb Cortex 18, 1856-1864.

[51] Razlighi QR, Habeck C, Steffener J, Gazes Y, Zahodne LB, Mackay-Brandt A, Stern Y (2014) Unilateral disruptions in the default network with aging in native space. Brain Behav 4, 143-157.

[52] Biswal BB, Mennes M, Zuo XN, Gohel S, Kelly C, Smith SM, Beckmann CF, Adelstein JS, Buckner RL, Colcombe S, Dogonowski AM, Ernst M, Fair D, Hampson M, Hoptman MJ, Hyde JS, Kiviniemi VJ, Kotter R, Li SJ, Lin CP, Lowe MJ, Mackay C, Madden DJ, Madsen KH, Margulies DS, Mayberg HS, McMahon K, Monk CS, Mostofsky SH, Nagel BJ, Pekar JJ, Peltier SJ, Petersen SE, Riedl V, Rombouts SA, Rypma B, Schlaggar BL, Schmidt S, Seidler RD, Siegle GJ, Sorg C, Teng GJ, Veijola J, Villringer A, Walter M, Wang L, Weng XC, Whitfield-Gabrieli S, Williamson P, Windischberger C, Zang YF, Zhang HY, Castellanos FX, Milham MP (2010) Toward discovery science of human brain function. Proc Natl Acad Sci U S A 107, 4734-4739.

[53] Campbell KL, Grigg O, Saverino C, Churchill N, Grady CL (2013) Age differences in the intrinsic functional connectivity of default network subsystems. Front Aging Neurosci $5,73$.

[54] Mevel K, Landeau B, Fouquet M, La Joie R, Villain N, Mezenge F, Perrotin A, Eustache F, Desgranges B, Chetelat G (2013) Age effect on the default mode network, inner thoughts, and cognitive abilities. Neurobiol Aging 34, 12921301.

[55] Vidal-Pineiro D, Valls-Pedret C, Fernandez-Cabello S, Arenaza-Urquijo EM, Sala-Llonch R, Solana E, Bargallo N, Junque C, Ros E, Bartres-Faz D (2014) Decreased default mode network connectivity correlates with age-associated structural and cognitive changes. Front Aging Neurosci 6, 256.

[56] Ferreira LK, Busatto GF (2013) Resting-state functional connectivity in normal brain aging. Neurosci Biobehav Rev 37, 384-400.

[57] Jones DT, Machulda MM, Vemuri P, McDade EM, Zeng G, Senjem ML, Gunter JL, Przybelski SA, Avula RT, Knopman DS, Boeve BF, Petersen RC, Jack CR Jr (2011) Age-related changes in the default mode network are more advanced in Alzheimer disease. Neurology 77, 1524-1531. 
[58] Buckner RL, Snyder AZ, Shannon BJ, LaRossa G, Sachs R, Fotenos AF, Sheline YI, Klunk WE, Mathis CA, Morris JC, Mintun MA (2005) Molecular, structural, and functional characterization of Alzheimer's disease: Evidence for a relationship between default activity, amyloid, and memory. J Neurosci 25, 7709-7717.

[59] Greicius MD, Supekar K, Menon V, Dougherty RF (2009) Resting-state functional connectivity reflects structural connectivity in the default mode network. Cereb Cortex 19, 72-78.

[60] Ornish D, Lin J, Chan JM, Epel E, Kemp C, Weidner G, Marlin R, Frenda SJ, Magbanua MJ, Daubenmier J, Estay I, Hills NK, Chainani-Wu N, Carroll PR, Blackburn EH (2013) Effect of comprehensive lifestyle changes on telomerase activity and telomere length in men with biopsy-proven low-risk prostate cancer: 5-year followup of a descriptive pilot study. Lancet Oncol 14, 11121120.

[61] Eyre HA, Baune BT (2014) Assessing for unique immunomodulatory and neuroplastic profiles of physical activity subtypes: A focus on psychiatric disorders. Brain Behav Immun 39, 42-55.

[62] Black DS, Cole SW, Irwin MR, Breen E, St Cyr NM, Nazarian N, Khalsa DS, Lavretsky H (2013) Yogic meditation reverses NF-kappaB and IRF-related transcriptome dynamics in leukocytes of family dementia caregivers in a randomized controlled trial. Psychoneuroendocrinology 38 , 348-355.

[63] Naveen GH, Thirthalli J, Rao MG, Varambally S, Christopher R, Gangadhar BN (2013) Positive therapeutic and neurotropic effects of yoga in depression: A comparative study. Indian J Psychiatry 55, S400-S404.

[64] Sinha S, Singh SN, Monga YP, Ray US (2007) Improvement of glutathione and total antioxidant status with yoga. JAltern Complement Med 13, 1085-1090.

[65] Taylor VA, Daneault V, Grant J, Scavone G, Breton E, RoffeVidal S, Courtemanche J, Lavarenne AS, Marrelec G, Benali $\mathrm{H}$, Beauregard M (2013) Impact of meditation training on the default mode network during a restful state. Soc Cogn Affect Neurosci 8, 4-14.

[66] Brewer JA, Worhunsky PD, Gray JR, Tang YY, Weber J, Kober H (2011) Meditation experience is associated with differences in default mode network activity and connectivity. Proc Natl Acad Sci U S A 108, 20254-20259.

[67] Vandenberghe R, Gitelman DR, Parrish TB, Mesulam MM (2001) Functional specificity of superior parietal mediation of spatial shifting. Neuroimage 14, 661-673.

[68] Daselaar SM, Iyengar V, Davis SW, Eklund K, Hayes SM, Cabeza RE (2015) Less wiring, more firing: Lowperforming older adults compensate for impaired white matter with greater neural activity. Cereb Cortex 25, 983990. 